\title{
TRABAJOS DE INVESTIGACIÓN
}

\section{HIPÓFISIS Y SUPRARRENAL}

\section{Póster}

\section{Enfermedad de Addison asociada a} paracoccidioidomicosis. Reporte de caso

\author{
Delgado EN, Parra GA, Wandurraga EA, Sarmiento JG, Martínez C, García M. E, Tovar G.
}

FOSCAL - Endoriente. Bucaramanga, Colombia

Hombre de 56 años con cuadro de ocho meses caracterizado por pérdida de peso de $19 \mathrm{~kg}$, hiporexia e hiperpigmentación de piel, con empeoramiento del cuadro en los últimos tres meses con episodios de ortostatismo, astenia, dolor abdominal y vómito, que ha consultado en varias oportunidades a urgencias. Al examen físico presentaba tensión arterial de 70/54 mmHg, hiperpigmentación en cara, tronco, brazos, líneas palmares, carrillos, paladar y base de lengua. En los estudios paraclínicos se evidenció sodio sérico de $105 \mathrm{mmol} / \mathrm{L}$, potasio 7,04 mmol/L y cortisol: $0 \mathrm{mcg} / \mathrm{dl}$. Se hizo diagnóstico de insuficiencia suprarrenal primaria cursando con crisis addisoniana. Recibió manejo con líquidos endoveno- sos e hidrocortisona, con adecuada respuesta clínica. Tomografía computarizada de cuello (TC) evidenció aumento del tamaño de los ganglios yugulo-digástricos con pérdida del hilio graso, TC toracoabdominal con adenopatías en la región paratraqueal derecha, en la cadena ilíaca primitiva derecha e inguinales y marcado aumento del tamaño de las glándulas suprarrenales con una lesión focal en la glándula suprarrenal izquierda de $45 \times 20 \mathrm{~mm}$ de diámetro. Se realizó una biopsia adrenal guiada por endosonografía endoscópica con patología que reportó lesión necrohemorrágica positiva para levaduras multigemantes compatibles con paracoccidioidomicosis. Actualmente, en manejo con anfotericina B deoxicolato y posteriormente se cambiará a itraconazol oral. Además, recibe suplencia con prednisolona y fludrocortisona.

Póster

\section{Experiencia con cateterismo de senos petrosos en 2 centros hospitalarios de la ciudad de Medellín}

\section{Builes CE, Builes CA, Tobón CI, Castaño PA, Syro LV, Rojas N.}

Hospital Pablo Tobón Uribe, Hospital Universitario San Vicente Fundación, Universidad de Antioquia. Medellín, Colombia.

Objetivo: Describir las características demográficas y clínicas de los pacientes con hipercortisolismo en quienes se realiza un cateterismo de senos petrosos en dos centros de alta complejidad de la ciudad de Medellín y reportar los resultados de este procedimiento.

Diseño del estudio: Revisión retrospectiva de historias clínicas.

Lugar del estudio: Hospital Universitario San Vicente Fundación y Hospital Pablo Tobón Uribe.

Pacientes: Hipercortisolismo confirmado, con discrepancia entre pruebas bioquímicas y resonancia de silla turca.

Intervenciones: Cateterismo de senos petrosos.

Mediciones: ACTH basal, a los 3, 5 y 10 minutos posestímulo en senos petrosos y vena periférica con desmopresina o
CRH. Se tomó como control la prolactina en ambos senos petrosos y en vena periférica.

Resultados: Se presentan 13 casos, 90,9\% de los pacientes tenían hipertensión arterial y 77,8\% diabetes mellitus. El estudio bioquímico inicial apoyaba enfermedad de Cushing en $30 \%$ de los pacientes, y hubo adenoma menor de $5 \mathrm{~mm}$ por resonancia en $54,5 \%$ de los casos. Se realizaron 11 cateterismos con estímulo de desmopresina y 2 con CRH. El cateterismo fue exitoso en $84,7 \%$ de los casos. No hubo complicaciones derivadas del procedimiento ni efectos adversos con el uso de la desmopresina. De los cateterismos exitosos, el perfil bioquímico apoyó enfermedad de Cushing en 100\% de los pacientes.

Conclusión: El cateterismo de senos petrosos en nuestra población es un procedimiento seguro, y el uso de desmopresina, es útil y seguro como estímulo. De una población de pacientes con hipercortisolismo bioquímico, se logró confirmación de origen hipofisiario en todos los casos. 


\title{
Histoplasmosis diseminada en un paciente con diagnóstico de feocromocitoma. Reporte de caso
}

Silva J. D, Parra G. A

FOSCAL - Endoriente. Bucaramanga, Colombia

Paciente femenina de 50 años de edad, consulta a urgencias por clínica de siete meses de picos febriles cuantificados en 39 ${ }^{0} \mathrm{C}$, intermitentes, sin patrón característico, astenia y adinamia. Los últimos siete días con síntomas urinarios, palpitaciones y diaforesis. Al examen físico de ingreso con presión arterial 210/80 mmHg, taquicárdica, febril, con deshidratación grado 1. Se manejó en UCI como cuadro de urosepsis asociado a crisis hipertensiva, recibiendo manejo con labetalol, meropenem y vancomicina sin aislamiento microbiológico en cultivos. En los estudios paraclínicos se documenta ecografía abdominal con masa hipoecógena en el riñón izquierdo hacia el polo superior, metanefrinas en orina de $2.216 \mathrm{mcg} / 24$ horas, cortisol $25 \mathrm{mcg} / 24$ horas y TSH 1,8 mlU/L. Se tomó TAC abdominal con evidencia de lesión neoplásica retroperitoneal dependiente de la glándula suprarrenal izquierda, adenopatías retroperitoneales e imágenes esplénicas sugestivas de hamartomas esplénicos. Fue llevada a adrenalectomía y esplenectomía con patología de glándula suprarrenal concluyente para feocromocitoma. Estudio de lesiones esplénicas con tinción para Gomory sugestiva de infección micótica tipo histoplasmosis. Posquirúrgico con normalización de presión arterial y mejoría clínica; sin embargo, se toma TAC de tórax y abdomen de control con reporte de lesiones nodulares a nivel hepático y pulmonar en árbol de gemación con adenopatías mediastinales y abdominales. Se realizó LBA que fue normal, biopsia hepática y de ganglios mediastinales para estudio histopatológico y microbiológico con patología compatible con lesiones granulomatosas, que en contexto de lesión esplénica se interpretaron como histoplasmosis diseminada. Infectología indicó itraconazol durante 12 meses. Permanece asintomática adrenérgica, metanefrinas en orina de control 360/24 horas, evolución adecuada.

\section{Presentación Oral}

\section{Factores pronósticos en carcinoma adrenal en una cohorte retrospectiva}

\author{
Fierro Maya LF', González Clavijo $A M^{2}$, Carreño $J A^{3}$, Cuéllar $A A^{4}$
}

${ }^{1}$ Coordinador de la Unidad de Endocrinología Oncológica del Instituto Nacional de Cancerología. Bogotá.

${ }^{2}$ Endocrinóloga North West Salud total, Clínica Nogales. Bogotá.

${ }^{3}$ Jefe de la Unidad de Investigación Clínica del Instituto Nacional de Cancerología. Bogotá.

${ }^{4}$ Endocrinólogo del Instituto Nacional de Cancerología. Bogotá.

Contexto. El carcinoma adrenal es una neoplasia endocrina rara con una incidencia anual de 0,7 - 2,0 casos/millón de habitantes pero altamente agresiva. La supervivencia de estos pacientes parece estar principalmente impactada de manera desfavorable por el compromiso de márgenes quirúrgicos, el grado histológico, la secreción hormonal y favorablemente por el uso de mitotane adyuvante. Sin embargo, los resultados no parecen ser homogéneos en cada una de las cohortes publicadas. En este estudio se analizan las variables pronósticas mencionadas en la literatura y su impacto en los desenlaces clínicos en una seria retrospectiva de casos de una institución del país en el periodo 2008-2014.

Metodología: Estudio de cohorte retrospectivo, los pacientes con diagnóstico histológico de carcinoma adrenal atendidos en el Instituto Nacional de Cancerología entre el 1 de enero del 2008 y el 31 de diciembre del 2014.

Resultados: Se incluyeron en el estudio estadístico 15 pacientes. Las variables de invasión vascular KI 67\%, índice mitótico y estadio clínico se asociaron con un peor pronóstico, supervivencia libre de recaída y de supervivencia global. Por el tamaño de la muestra no fue posible calcular medidas de asociación estadística.

Conclusión: El carcinoma adrenal es una patología poco frecuente pero con elevada mortalidad determinada principalmente por la biología del tumor y el momento del diagnóstico. 